\title{
Factors Affecting Customer Attachment in the Marketing Communication and its Implementation on Tourism Sector
}

\author{
MEHMET SERDAR ERCIŞ \\ Faculty of Communication \\ Ataturk University, Turkey
}

\begin{abstract}
This research aims to identify the efficiency of the variables that positively or negatively affect customer attachment, which constitutes a significant place among the goals regarding marketing communications practices. The hypotheses regarding the research were tested through a questionnaire given to the executives of the 141 Group A travel agencies active in the distribution sector in Turkey. The research has shown that trust felt for the seller, positive and satisfying seller-customer relations, cooperation, mutual benefits, and empathizing have positive effects on creating customer attachment; while opportunist attitudes, potential conflicts between the seller and the customer, and risks regarding the future may affect customer attachment negatively.
\end{abstract}

Key Words: Marketing Communication, Customer Attachment, Tourism, Tourism sector

\section{Introduction}

Increasing competition and similar products and services of our day have made the significance of diversifying products and services clear for businesses; and decreasing prices and falling profits have caused a customer centered twist in business attitudes. Creating long term relations with the customers and turning these relations into an attachment, in other words, developing customer attachment to a firm, brand or product not only has become one of the major goals in marketing communications practices with this new approach, but also has become the key to profit in marketing communications activities. In this outlook, it is expected that this research will contribute to marketing communications activities and practices, customer oriented service giving from the perspective of marketing communications management, and creating marketing communications strategies aiming customer attachment. 


\section{Factors Affecting Marketing Communication and Customer Attachment Marketing Communication}

Marketing communication enhances all means of communication between the firm and the target market, increases the tangibility of the product-service combination, creates or observes customer expectations, and convinces the customers for purchase. It is especially important here to pay attention to the phrase "between the firm and the target market", because it emphasizes that communication is a "two-lane road". In other words, communication does not only include the actions that the firm undertakes for communication, but also the feedback from the market that comes in return to the efforts of the firm. Through this feedback, the target market provides information regarding how the firm communicates with them and how it serves the services it promises to give.

Secondly, the phrase "makes increases the tangibility of the product-service combination" points out that due to the abstract feature of the service, the words and images used in communication constitutes the physical manifestation of the product and makes it concrete.

Thirdly, the phrase "creates or observes customer expectations" explains that communication not only creates expectation, but also produces warning for the firm when the needs are not satisfied or are changed.

Finally, the phrase "convinces the customers for purchase" reveals that, although the aims, especially of publicity and public relations, include establishing temporary communication, creating awareness and improving company image; the primary aim of all marketing communications is to encourage the customers for purchase.

All approaches and practices of marketing activities are considered communication. Just as the product design may send different messages to the customer, the distribution itself is also a type of communication. Therefore, the most common method of understanding marketing communications could be looking at the stages of marketing. Marketing communications, in addition to product design, also includes price, distribution, publicity and in-shop activities. This process continues with the customer's purchase, and stretches to the post-purchase services. Regarding services, when looked at the aforementioned features of service, the 
design, location, and style of service, i.e. product purchase and consumption happens to be simultaneous, and this situation signifies marketing communications yet again.

One of the major goals regarding marketing communications practices is to create and practice strategies for customer attachment. At this stage marketing communications is responsible for naming the factors that will create customer attachment and ensure its continuity, and implement these factors into practice.

\section{Factors Affecting Customer Attachment}

Ensuring customer attachment plays a central role in marketing communications activities and is one of the most significant features of relationship marketing models. The main aim here is to create customer attachment by forming long-term relationships. Therefore, designation of the factors affecting customer attachment is very significant for constructing and sustaining a relationship. The parties have to be attached to each other. This attachment may be described as an emotional nearness felt for an organization and its depth may differ according to the nature of the relationship. Customer attachment plays a central role in marketing communications and is one of the most decisive features of marketing communications aims. The attachment depends on the definite or indefinite promises between the parties.

Factors affecting customer attachment can be categorized in two groups as variables that affect the attachment positively and variables that affect the attachment negatively. Variables affecting the attachment positively are trust, communication, satisfaction, cooperation, reciprocity, empathy, loyalty, non-opportunist attitudes and actions, a risk-free environment, and harmony between the parties. Variables affecting the attachment negatively are opportunist attitudes, conflicts between the parties, and risk.

\section{The Aim and Scope of the Research}

The primary aim of this research is to examine the factors affecting building customer attachment between the producers and the intermediaries taking part in product distribution. Other aims are to prove the applicability of marketing communications on tourism sector, and to draw forward the efficiency of the factors affecting customer attachment between the Group A travel agencies and the lodging businesses serving these agencies. The improving marketing approach of our day has made travel agencies a significant customer of hotels. 
Travel agencies are intermediary businesses that serve in the name of the customer and seek profit in the distribution sector. The scope of the research is the relations between the lodging businesses that serve in the tourism sector and the Group A travel agencies. For testing the project model, which is prepared to best suit the aims of the project, and for testing the hypotheses, a questionnaire was given to the nationwide Group A travel agencies.

\section{The Project Sample, Method and Hypotheses}

The research covers 2328 travel agencies that serve in various locations in Turkey. The data was collected through a questionnaire. A wide ranging literature review was held while preparing the questionnaire, and after a thorough analysis, the scale factors that best present the connections between the variables were prepared. The results of the questionnaire were written following the required adjustments and arrangements in forming the questionnaire. The variables and questions affecting the loyalty variable are ranked according to the five point likert scale, and the respondent was asked to make only one choice. The final section of the questionnaire included one confining question, and one last question for receiving general information.

The information and addresses of the Group A travel agencies are taken from the Association of Turkish Travel Agencies (TURSAB). Each agency is given a number, the numbers are written on pieces of papers and the papers are thrown into a bag. Numbers randomly picked from the bag formed the sample volume, and the agencies forming the sample volume received the questionnaires. The surveys were conducted using two methods-via mail and face to face. When the surveys were sent via mail, the agency managers were asked to fill them out. When the surveys were conducted face to face, the directors of agencies were interviewed and the survey was conducted directly by the researcher himself. Observation during the face to face surveys has allowed control over the truthfulness of the information presented. Of all the surveys sent via mail, 75 were sent back. 4 out of 75 surveys were not evaluated for they were assessed to be filled out either incompletely or incorrectly. As for the face to face surveys, the questionnaires were filled out through in person interviews with managers of 70 agencies. 
Additionally, in the light of the information gathered through the observation method, some criteria regarding agency choice have gained significance, and the rest of the research was conducted accordingly. A total of 141 interviews were held.

Ten hypotheses were developed regarding the research. The hypotheses were developed following a wide ranging literature review, and were categorized as those that affect customer attachment positively and negatively.

$\mathrm{H}_{1}$ : Trust has a positive effect on building customer attachment.

$\mathrm{H}_{2}$ : Effective communication has a positive effect on building customer attachment.

$\mathrm{H}_{3}$ : Satisfaction has a positive effect on building customer attachment.

$\mathrm{H}_{4}$ : Cooperation has a positive effect on building customer attachment.

$\mathrm{H}_{5}$ : Loyalty has a positive effect on building customer attachment.

$\mathrm{H}_{6}$ : Empathy has a positive effect on building customer attachment.

$\mathrm{H}_{7}$ : Reciprocity has a positive effect on building customer attachment.

$\mathrm{H}_{8}$ : Opportunist attitude has a positive effect on building customer attachment.

$\mathrm{H}_{9}$ : Conflict has a positive effect on building customer attachment.

$\mathrm{H}_{10}$ : Risk has a positive effect on building customer attachment.

\section{Data Analysis}

The research holds customer attachment as the dependant variable, and trust, communication, satisfaction, cooperation, reciprocity, loyalty, empathy, opportunist attitude, conflict and risk as the independent variables. The trustworthiness tests and factor analyses of the questions were completed regarding these variables. Afterwards, the research variables were subjected to correlation analysis and the interconnections between them were presented. Lastly, the relations between the dependant variable - i.e. customer attachment - and the factors that were assumed to affect this variable positively or negatively were examined. Hence, the linear regression method was used for testing the theoretic model and the hypotheses.

While making the regression analyses, in order to test the sensitivity of the constructed model against the variables, the independent variables that affect customer attachment positively were taken into analysis firstly. Then, all variables that affect customer attachment positively or negatively were incorporated into the analysis, through which their efficiency levels were presented. 
According to the factor analysis results of the independent loyalty variable, the variable can be viewed in two categories. The topics discussed within these categories include the originality of the producing company and its willingness for a long-term relationship for the first sub-factor which includes six problems, and loyalty to the producing company and the efforts put in for the relationship for the second sub-factor which includes five problems. According to the analyses, the credibility percentage of the first factor is as high as $82 \%$, and for the second factor the percentage is 72 .

At the end of the analyses, it is observed that the variable satisfaction, which includes 15 problems, can be viewed in three sub-factors. The first sub-factor consists of 5 questions about eagerness and satisfying needs, the second sub-factor consists of 6 questions about level of service quality, the third sub-factor consists of 4 questions about creating value and opportunity. The result of the reliability analysis, for the first sub-factor, was $77 \%$; for the second, was $80 \%$; and for the third factor, was $67 \%$.

On another note, it is discovered that the trust variable, which consists of 7 questions, has a credibility coefficient of alpha $=.81$; the communication variable, which consists of 8 questions, has a credibility coefficient of alpha=.84; the cooperation variable, which consists of 7 questions, has a credibility coefficient of alpha=.84; the reciprocity variable, which consists of 5 questions, has a credibility coefficient of alpha=.76; the loyalty variable, which consists of 5 questions, has a credibility coefficient of alpha=.70; the conflict variable, which consists of 7 questions, has a credibility coefficient of alpha=.76; and the risk variable, which consists of 5 questions, has a credibility coefficient of alpha=.69. All these variables are categorized under the same factor.

Table 1 shows the one-on-one correlation relationships between the customer satisfaction variable and all other variables. The correlation coefficients show the degree of relations between the variables. These data show the level of expressiveness at the degrees of $\mathrm{p}<.01$ or $\mathrm{p}<.05$, and whether these relationships are positive or negative. As is seen in the data gathered from the table, statistically meaningful and high correlation coefficients are recorded between the customer attachment variable and all other variables - as was foreseen in the hypotheses. 
Moreover, all the independent variables in the research model and the dependent variable customer attachment were subjected to regression analysis, the results of which can be seen in Table 2.

The beta coefficients and their levels of expressiveness are as presented in Table 2. As seen in the chart, the $\mathrm{R}^{2}$ level is 0.80 and the $\mathrm{F}$ value is 56 . Thus, the independent variables in the research model of the $\mathrm{R}^{2}$ and $\mathrm{F}$ values (trust, communication, satisfaction, cooperation, loyalty, empathy, reciprocity, opportunist attitude, conflict and risk) are proven to be sufficient in explaining the dependant variable customer attachment-which also shows that the results of the research were meaningful and sound. When the data on table 2 is examined, the results can be evaluated as below. 
Table-1: Correlation, Average and Standard Deviation Values of Variables,

\begin{tabular}{|c|c|c|c|c|c|c|c|c|c|c|c|}
\hline Factor & 1 & 2 & 3 & 4 & 5 & 6 & 7 & 8 & 9 & 10 & 11 \\
\hline Attachment & - & & & & & & & & & & \\
\hline Trust & $.639 * *$ & - & & & & & & & & & \\
\hline Communication & $.752 * *$ & $.700 * *$ & - & & & & & & & & \\
\hline Satisfaction & $.815^{* * *}$ & $.720 * *$ & $.799 * *$ & - & & & & & & & \\
\hline Cooperation & $.748 * *$ & $.734 * *$ & $.799 * *$ & $.854 * *$ & - & & & & & & \\
\hline Loyalty & $.655^{* * *}$ & $.363^{* * *}$ & $.372 * *$ & $.461 * *$ & $.359^{* *}$ & - & & & & & \\
\hline Empathy & $.678^{* * *}$ & $.721 * *$ & $.691 * *$ & $.792 * *$ & $.808 * *$ & $.298 * *$ & - & & & & \\
\hline Reciprocity & $.675^{* *}$ & $.753 * *$ & $.715 * *$ & $.811 * *$ & $.780 * *$ & $.252 * *$ & $.764 * *$ & - & & & \\
\hline $\begin{array}{l}\text { Opportunist } \\
\text { attitude }\end{array}$ & $-637 * *$ & $-.658 *$ & $-.676^{* * *}$ & -.709 ** & $-.728 * *$ & $-.268^{* *}$ & $-.703 * *$ & $-.702 * *$ & - & & \\
\hline Conflict & $-.652 * *$ & $-.608^{*}$ & $-.636^{* *}$ & $-.602 * *$ & $-.628 * *$ & -.142 & $-.598 * *$ & $-.584 * *$ & $-.718^{\text {*** }}$ & - & \\
\hline Risk & $-.367 * *$ & $-.428 *$ & $-.436^{* * *}$ & $-.398^{* *}$ & $-.328 * *$ & $-.172 * *$ & $-.398^{* * *}$ & $-.337 * *$ & $-.419^{* *}$ & $-.589^{* *}$ & - \\
\hline Average & 3.39 & 3.56 & 3.79 & 3.78 & 3.89 & 3.42 & 3.56 & 2.76 & 2.87 & 2.86 & 2.22 \\
\hline S.D & .57 & .63 & .60 & .51 & .63 & .69 & .69 & .55 & .62 & .64 & .71 \\
\hline $\mathrm{N}$ & 141 & 141 & 141 & 141 & 141 & 141 & 141 & 141 & 141 & 141 & 141 \\
\hline & & & & & & $* * .01$ & & & & & \\
\hline & & & & & & $* .05$ & & & & & \\
\hline
\end{tabular}


Table 2: The Variables That Affect Customer Attachment

\begin{tabular}{|c|c|c|}
\hline Independent Variables & Beta & Significance (p) \% \\
\hline Trust & $.122^{*}$ & .03 \\
\hline communication & $.144^{*}$ & .02 \\
\hline Satisfaction & $.326^{* *}$ & .00 \\
\hline Cooperation & .111 & .10 \\
\hline Loyalty & $.336^{* *}$ & .00 \\
\hline Empathy & .005 & .47 \\
\hline Reciprocity & .039 & .30 \\
\hline Opportunist attitude & $-.125^{*}$ & .03 \\
\hline Conflict & $.190^{* *}$ & .00 \\
\hline Risk & $-.085^{*}$ & .04 \\
\hline Dependent Variable :Customer Attachment $* * .01-* .05$ \\
$\mathrm{R}^{2}=0.80 \quad$ F= 56
\end{tabular}

The level of expressiveness of the dependence of the variable trust is defined as beta.122 and $\mathrm{p}<.05$. The meaningful relationship between these variables is seen to affect dependence positively, which proves the hypothesis that the trust felt for the seller has a positive effect on customer attachment. Thus, the $\mathrm{H}_{1}$ hypothesis, "Trust has a positive effect on building customer attachment," is accepted.

One hypothesis developed through the study was that effective communication has a positive effect on customer attachment. The results of the analysis has shown that the communication is effective on customer attachment to the level of expressiveness $\mathrm{p}<.05$ (beta.144). Hence, developing an efficient communication improves attachment, which proves our hypothesis. The $\mathrm{H}_{2}$ hypothesis, "Effective communication has a positive effect on building customer attachment," is accepted.

One other hypothesis in the research is developed in order to show the connections between customer satisfaction and customer attachment. The results of the regression analyses have shown that there exists a meaningful and positive relationship between the satisfaction 
variable and customer attachment. The satisfaction variable affects customer attachment to the expressiveness level of be-ta.326 and $\mathrm{p}<.01$. Therefore one might state that the high satisfaction level provided to the customer is effective in developing customer attachment. In the light of this data, the $\mathrm{H}_{3}$ hypothesis, "Satisfaction has a positive effect on building customer attachment," is accepted.

The effectiveness of the cooperation variable on customer attachment was also researched. At the end of the analyses, no correlation between cooperation and customer attachment was found. Therefore, the $\mathrm{H}_{4}$ hypothesis, "Cooperation has a positive effect on building customer attachment," is rejected.

It was found out that the loyalty variable is effective on customer attachment to a beta coefficient level as high as 336 and an expressiveness level of $\mathrm{p}<.01$. A meaningful and positive correlation between the loyalty variable and customer attachment was found. According to the results, it can be noted that loyalty has a strongly positive effect on customer attachment. Thus, the $\mathrm{H}_{5}$ hypothesis, "Loyalty has a positive effect on building customer attachment," is accepted.

No meaningful correlation between the empathy variable and customer attachment was found. Therefore, the $\mathrm{H}_{6}$ hypothesis, "Empathy has a positive effect on building customer attachment," is rejected.

The effects of reciprocity variable on customer attachment were also examined, yet after the regression analyses, no correlation between these variables was found. Thus, the $\mathrm{H}_{7}$ hypothesis, "Reciprocity has a positive effect on building customer attachment," was rejected.

Opportunist attitude, which was assumed to have a negative effect on customer attachment, was also examined. The results has shown that opportunist attitude effects customer attachment negatively to the meaningfulness level of $\mathrm{p}<.5$, with a beta coefficient of -.125 . Thus, the $\mathrm{H}_{8}$ hypothesis, "Opportunist attitude has a positive effect on building customer attachment," is rejected. 
One other point that deserves attention is the rejection of the $\mathrm{H}_{9}$ hypothesis, "Conflict has a positive effect on building customer attachment." A meaningful and positive correlation between conflict and customer attachment was defined. The correlation was found out to be at a meaningfulness level of beta.190 and $\mathrm{p}<.01$.

The risk variable was also assumed to have a negative effect on customer attachment. The research has pointed to a negative correlation between the variable risk and customer attachment - a meaningfulness level of $\mathrm{p}<.05$ and a -.085 beta value. In this regard, the $\mathrm{H}_{10}$ hypothesis, "Risk has a positive effect on building customer attachment," was rejected.

\section{Conclusion and Recommendations}

It can be observed that traditional marketing approach has lost its validity in the competitive conditions of our day, and these conditions have caused companies to seek new approaches. Strong competition, homogenization of products and services, and maturing of markets make differentiation and originality hard for firms that are active in both product and service industries. Providing solely technical solutions to problems form customers is not enough by itself for gaining advantage in competition, and increasing and sustaining market share. To gain competition advantage and develop customer attachment, various value-added services should also be given prior to or during an operation. In this regard, the significance of marketing communications comes to the front. Marketing communications practices where loyalty has a central role and the guiding role of processors would be significant here. The loyalty factor between the producers in the distribution channel, and the intermediary firms that happen to be the customer of the producers, appears to be fairly significant.

According to the results of the research, the variables trust, satisfaction, loyalty, communication, opportunist attitude, conflict and risk are effective on attachment. According to the analyses, the loyalty factor affects attachment highly and positively — which shows us that the level of attachment between the seller and the buyer will increase. In a world where a big competition is in place, market resources are insufficient, and the sustainability of a relationship is hard, it is clear that the parties will be eager in reaching their aims and goalswhich, clearly, is an effective factor in creating long-term relationships. One major concern here is avoiding an extreme power imbalance regarding the dependence between the parties. 
On another note, the research has also showed that trust felt for the seller, level of satisfaction and effective communication also increase the level of attachment. One of the most important elements in a relationship is creating a trustworthy environment. The parties would pursue their relationship only as long as they trust each other. The customer may not know everything in detail or may not be able to follow. Therefore, avoiding behavior that may cause trust flaws and putting in effort to deepen trust are essential for developing trust. Solving problems regarding either the product or the services, the level of satisfaction provided to the customer through constructing strategies and policies in line with the needs of the customer, would all positively affect the establishment and development of attachment. It is impossible to establish and develop healthy customer relations without effective communication. Communication requires the sharing of ideas, feelings, thoughts and information. Customers need information before, during and after the purchase. An open, clear, and continuous communication has a valuable role in developing long term relationships, and therefore in establishing attachment. Thus, effort must be put in to ensure communication at all times.

The findings in the research have shown that opportunist attitude has a negative effect on establishing long term relationship as well as attachment. Constructing strategies and policies based on the weaknesses of the customer will surely effect attachment negatively. Moreover, it is assessed that the risk factor and an ambiguous future environment would affect attachment negatively. The customer wants to see the future of his relationships, to reach the information he seeks and act accordingly. Risks and ambiguities have to be minimized in long term relationships.

Some interesting results were also found about the conflict variable. The hypothesis that the buyer-seller disagreements would affect customer attachment negatively, by the time the statistical analyses were completed, was rejected. While there is a meaningful correlation between conflict and customer attachment, contrary to what was foreseen, it was found out that conflict affected attachment not negatively, but positively. The situation can be explained as follows: the research emphasizes the positive and negative effects of conflict on relationships. The discussions in the literature about the subject still continue. However recent studies show that when the conflicts are well-managed and well-directed, contrary to the destructive effects of conflicts, it is possible to grant flexibility for alternative decisions, to open the space for creativity and innovation by allowing different ideas and thoughts, and 
hence to have the relationship grow in a positive direction. Thus, it is possible to say that the conflicts that may rise in the absence of other variables can affect customer attachment positively.

In the light of the above information, it is absolutely vital that to reach their aims and goals, the members in the distribution channel restructure their relationships, and construct strategies and policies accordingly.

\section{References}

Don E. Schultz, Stanley Tannenbaum. (2003). Integrated Matketing Communications, Chicago: NTC Pup., 2003, s. 45-46.

Morgan, Robert M.; Shelby D. HUNT. (2004). "The Commitment-Trust Theory of Relationship Marketing”. Journal of Marketing. Vol.58. (July). 20-38.

Palmer, Adrian. (1994a). "Relationship Marketing: Time to Enrich the Marketing Curriculum”. Journal of Marketing Education.. Summer. Vol.16. No.2. 34-41.

Relationships: The Role of Commitment”. Journal of Industrial and Business Marketing. Vol.13. No.1. 406-423.

Robert C. Lewis ve Richard E. Chambers. (2000). Marketing Leadership in Hospitality, Third

Edition, NewYork: John, Wiley \& Sons, s.444

Takala, Tuomo. (2006). “An Alternative View of Relationship Market-ing: A Framework for Ethical Analysis”. European Journal of Marketing. Vol.30. No.2. 45-60.

Wetzels, Martin; Ko De RUYTER, Marcel Van BIRGELEN. (1998). “Marketing Service

Relationships: The Role of Commitment”. Journal of Industrial and Business Marketing. Vol.13. No.1. 406-423.

W.D. Wells ve D. Prensky. (2007). Consumer Behavior, NewYork:John Wiley \& Sons, s. 427

Wisner, B. (2006). Applied Marketing, Newjersey: Prentice Hall, 2006, s.430 